\title{
PREVENTION OF FOOT DEFORMITIES
}

\author{
By T. T. STAMM, F.R.C.S.
}

\author{
Orthopaedic Surgeon, Guy's Hospital.
}

\begin{abstract}
NOW that the magnitude of the foot problem has received more general recognition, much greater interest is being taken in the development of preventive measures. A number of local authorities are already considering the institution of schemes for the detection and treatment of foot defects in their early stages. However, unless those who organize and carry out such work have a very clear idea of the nature and aetiology of the defects that cause disability in the adult foot, their efforts will be ineffective and wasteful of time and money.

It is therefore necessary first to be able to classify foot defects in the order of their frequency and the severity of the symptoms to which they give rise, and then to trace their mode of development, and finally to assess the factors responsible.

Fortunately recent surveys have not only brought to light the frequency of foot ailments amongst the population but have also provided factual information about their relative frequency and severity at different age periods.
\end{abstract}

\section{Some generalizations}

Before discussing individual conditions it is possible to make the following helpful generalizatiohs.

(1) Mechanical defects do not give rise to symptoms in children. The significance of defects noticed in the feet of children can therefore be assessed only by what is known of their likely subsequent history. Such knowledge is therefore an essential part of the quipment of those who carry out inspections of the feet of children.

(2) Surveys have shown that whereas in children defects affecting the region of the long arch are the abnormalities most frequently noticed, by adolescence they have become outnumbered by defects in the region of the forefoot and toes, while in the adult the latter are by far the commonest cause of pain and disablement.

(3) The hallux valgus complex is much the commonest of all causes of pain in the adult foot and affects women more commonly than men in the proportion of $10: 1$.

(4) The hallux valgus complex is not encountered in clinical practice as a cause of pain in people who do not wear shoes.

It must be accepted that no amount of care and attention could obviate all foot troubles. In an imperfect world the most we can hope to achieve is to reduce the incidence and severity of those few conditions which we know are responsible for the majority of foot ailments. We shall achieve much more good if our attention and care is concentrated on these selected defects, than if every noticed deviation from the normal is treated as of equal importance.

There are of course a number of minor foot ailments which can be dealt with simply and effectively by routine methods. Such transient ailments do not present any special problems. However, the major causes of foot disability require individual consideration, for they will need all our care and understanding if they are ever to be brought under control in the conditions of modern society.

These conditions can be roughly grouped into two main categories; (1) long arch defects; and (2) defects of the forefoot and toes. Although the latter have been shown to comprise not only the most frequent but also the most crippling of the affections of the foot, it will be more convenient to consider first those defects which primarily concern the long arch.

\section{Long arch defects}

A true flattening of the long arch sufficient to constitute a deformity is uncommon. It occurs congenitally as a result of abnormalities of the talus or the presence of a calcaneonavicular bar. It also occurs as a result of disease, the commonest being the rather obscure condition known as "spasmodic valgus", in which the foot becomes fixed in an exaggerated valgus attitude due to long continued spasm of the peronii.

An appearance of flat-footedness due to defective posture is however extremely common and in the majority of young children it is of little significahce. The appearance is due primarily to the fact that the foot has been allowed to roll over on to its inner border by a movement of eversion at the subtalar joint. The long arch is thus obscured because it is lying over on its side. This however is not the whole story for if the foot was everted as a whole, its outer border would rise off the ground. In fact this does not occur, the forefoot remaining plantar grade. Since the back part of the foot has become everted while the forefoot has not moved, the forefoot must be relatively inverted (or supinated) in relation to the "back foot". Thus the relaxed flat-footed attitude is the result of eversion of the back part of the foot, combined with an equal and opposite inversion of the forefoot upon it. So far as the relationship of the forefoot to the ground is concerned, these two rotary movements in opposite directions cancel out and the forefoot remains plantargrade.

The change from this relaxed flat-footed attitude to the strong fully arched posture is achieved by inversion of the back part of the foot combined with an equal degree of eversion of the forefoot. In contrast to the movements producing the flat-footed attitude which are passive, and imposed by body weight, these are active movements. They are carried out primarily by tibialis posterior and peroneus longus respectively. Since these are rotary movements about an antero-posterior axis the long arch is not so much raised or lowered, as screwed up or unscrewed.

The fully arched "screwed up" posture can only be ${ }^{\circ}$ maintained by active muscle tone. If muscle tone is defective the foot will naturally collapse into the relaxed unscrewed posture, so far as the tightness of its ligaments will allow. Since nearly all young children are posturally lazy they nearly all look flat-footed when standing at rest. It is only when this relaxed posture persists unduly or is present in an exaggerated degree that it has any significance. In such cases it becomes necessary to seek the cause.

Defective foot posture in children

The commonest causes of defective foot posture in a child are the following.

Knock knees and bow legs.-Three common variants from the normal are likely to be observed when any group of children under the age of ten are examined.

Genu valgum.-Some degree of knock knee, most noticeable on standing is extremely common in young children. A generation ago they ran a grave risk of being supplied with irons and night splints. It is now recognized 
that they nearly all grow out of it by the age of ten. Most that they help themselves to do so by turning their feet in. If they do adopt this "pigeon toed" attitude they can safely If the left to look after themselves. If , however, they give way to the deformity and allow their feet to roll out into a way to flat-footed attitude, an inside wedge to the heel of valgus flat-foot the sole) with a valgus lift in the shoe will help to correct their posture. Provided there is no increase in the deformity when they are re-examined a year later no other measures are necessary.

Bowed tibiae.-The bowing occurs in the lower third of the bone and is usually associated with some degree of medial rotation. There is a secondary valgus of the foot when the child stands, yet the feet do not point outwards owing to the rotation of the tibiae. This is a congenital deformity, which soon corrects itself. This is fortunate, as it is not possible to correct the deformity by any measures less than operation.

Bow legs.-In the commonest type the deformity occurs at the upper end of the tibia and is associated with a lateral rotation of the tibia below this point. As a result, if the child stands with the knees pointed forwards the feet are swung out laterally. Whereas if the feet are brought together in line, the knees face inwards and there is an apparent bow leg. Although this makes the child look awkward and "splay footed", interference is rarely called for, except in extreme cases. Very occasionally, however, the deformity does persist, and, especially in girls, merits correction by osteotomy at the upper end of the tibia.

"Short Tendo Achilles".-A relative shortness of the calf muscles is commonly found in children and often persists into adult life. In such cases the foot cannot be dorsiflexed to a right angle at the ankle joint when the muscles are in a state of normal tone, as when standing. In order to get the heel to the ground the foot has to be swung out at the subtalar joint, in order to get the benefit of the extra range of dorsiflexion which occurs at the end of this eversion movement. The foot is thus forced to adopt a valgus attitude. The condition is referred to as "valgus secondary to short Tendo Achilles", or more accurately as "valgus secondary to equinus" as it is the muscles not the tendon which are short. It is important that the true nature of the apparent flat-footed appearance to which it gives rise is appreciated, for the usual so called "flat foot" exercises in which the child is encouraged to walk about on tip toe can only do harm by inducing still tighter tone in the calf muscles. In fact just the opposite is indicated; that is to say, the child should be encouraged to walk on the heels with the foot elevated, thus promoting reciprocal relaxation of the calf mucles by active contraction of the extensors.

Supination of the forefeet.-An inversion twist to the forefoot is a common component of many varieties of club foot. It may occur alone, or more commonly, in association with some degree of dorsiflexion or "calcaneus" deformity. It is not an obvious deformity and rarely is anything abnormal noticed until the child begins to walk.

If the forefoot is inverted, then, in order that it may rest flush on the ground, the foot as a whole must be everted. The foot is thus forced to adopt the weak valgus or flatfooted attitude. It is in fact congenitally "unscrewed". Attempts to correct the flat-footed appearance by promoting inversion of the foot will, if successful, cause the inner border of the forefoot (that is the "ball" of the foot) to rise off the ground. In order to get something on to the ground on the inner side to steady the foot, the child will flex the great toe, thus using the pad of the toe instead of the ball of the foot as a weight bearing point. This throws a severe strain on the great toe joint itself and very soon will cause degenerative changes to occur leading ultimately to a hallux rigidus.

Thus, again, ill-advised treatment for apparent "flat foot" can only do harm, if it achieves anything at all.
The condition does present a difficult problem for which no final answer has been found. In marked cases in young children repeated manipulation and plaster fixation may prove successful. In milder cases reversed wedges, that is inside heel and outside sole, are useful, together with exercises designed to correct both primary and compensatory deformities by a combined contraction of tibialis posterior with peroneus longus. This is not an easy action to teach, and requires the assistance and supervision of a trained physiotherapist.

\section{Forefoot disabilities \\ Hallux rigidus}

In this condition the great toe joint has become stiff as a result of arthritic changes due to previous injury or to long standing overstrain on the joint.

The commonest cause of the latter is the "supinated forefoot" discussed above. Any other condition which denies the foot a stable area for weight-bearing under the ball of the foot will also induce flexion of the great toe to provide an alternative area under the pad of the toe itself, and will lead to the same end result, namely degeneration and arthritis of the great toe joint.

The only other condition which need be mentioned here is another congenital anomaly. In this, the first metatarsal is unduly mobile like the metacarpal of the thumb, and thus becomes displaced upwards when weight is borne on the foot. Again the toe itself is flexed in an attempt to provide stability while the metatarsal becomes fixed. in an elevated position. In this condition again misguided attempts to correct the associated flat foot can only do harm.

\section{The hallux valgus complex}

Although the aetiology of this condition is still not fully understood the following facts are recognized.

(a) There are certain types of feet which are congenitally prone to develop this deformity. The commonest is the foot that has a short and varus first metatarsal. There is little abnormal to be noticed in the foot of the young child, except that the forefoot looks rather broad and there may be an unduly wide cleft between the first and second toes. Another, but less common type is the long narrow unstable foot that tends to fall over into a valgus attitude on weight bearing. In some cases the toe itself is not only long but has some valgus angulation at the interphalangeal joint.

(b) In none of the cases of congenitally prone feet is there any valgus deformity of the toe at birth. The deformity of the toe itself is secondary and develops during childhood and adolescence.

(c) Although obvious deformity may be present by the age of ten years, the most rapid deterioration of the foot occurs during adolescence.

(d) Footwear, both shoes and socks, appears to be the most important factor in determining whether and to what extent deformity will occur in feet that are congenitally susceptible.

(e) The fashionable women's shoe with a high heel to provide a slope for the foot to slide down, and a toe cap designed as a $\mathrm{V}$ with a central point, is a perfect instrument for producing a hallux valgus deformity.

$(f)$ The condition is ten times more common in women than in men.

When considering the measures that should be taken to deal with this progressive and crippling condition it must be borne in mind that no treatment, operative or otherwise, has yet been evolved which will ensure correction of either the primary or the secondary deformities once they have become established. The emphasis must therefore be on detection and prevention rather than on treatment; detection by the regular inspection of the feet of school children, prevention mainly by advice and supervision of their foot- 
wear. These measures are the proper concern of the school and public health authorities, not the hospital clinics. Specialist advice should be sought only when the deformity progresses in spite of adequate care and supervision.

\section{Claw toes and pes cavus}

Clawing of the toes is a condition that results from paralysis or weakness of the intrinsic muscles (the interossei and lumbricals). As a result of the unopposed action of the long flexor and extensor muscles the toes become buckled into the clawed attitude. This buckling effect is transmitted back to the foot itself causing the secondary cavus deformity. The whole effect is similar to that of a folding screen which is drawn together by two cords.

While this condition may follow frank paralysis, as in cases of anterior poliomyelitis, or may develop gradually in progressive diseases such as Freidreich's ataxia or the muscular dystrophies, it more often develops without any obvious cause, and may then be the result of a transient peripheral neuritis due to one of the fevers, such as scarlet fever or diphtheria.

Although it may give rise to considerable disablement, it is fortunately more amenable to treatment than most foot deformities. If the paralysis has been transient or partial, much can be done by remedial physiotherapy, while even the severest cases can be satisfactorily dealt with surgically provided the deformities have not been allowed to become fixed. Since pain is a late symptom advice is rarely sought at an early stage. It is therefore only by routine inspection that cases will be detected at an early stage when treatment will be most effective.

\section{Retracted toes ("The signpost foot")}

This is a peculiar condition which is often confused with claw toes. It differs from it however in that although the toes are acutely dorsifiexed at the metatarso-phalangeal joints, there is little or no abnormal flexion of the interphalangeal joints. It seems to be due to overaction of the long extensors of the toes in an effort to supplement the action of tibialis anterior and peronii. The great toe itself is unaffected and remains straight, hence the term "signpost foot". It should be regarded as a sign of muscle unbalance in the foot and merits expert advice.

\section{Conclusions}

This brief discussion of the more common and important defects of the foot leads to the following conclusions.

(1) The foot problem as a whole can only be tackled successfully and economically by the adoption of preventive measures rather than by further expansion of facilities for the treatment of established disabilities.

(2) This implies an adequate organization for the detection of foot defects in their early stages by the regular inspection of the feet of school children.

(3) Such inspections to be effective must be carried out by those who have an adequate understanding of the nature and significance of any abnormalities detected.

(4) The treatment indicated in the majority of cases consists essentially in ensuring adequate care and supervision while the foot is growing and developing.

(5) This is properly the concern of the school and public health authorities, not of the hospital clinics.

(6) Cases should only be referred to specialist clinics when the above measures fail.

(7) Treatment such as special exercises, or supports, should not be prescribed indiscriminately and without careful diagnosis or they may do more harm than good.

(8) While the responsibility for carrying out any schemes of preventive care must fall principally on medical officers of health, school doctors and their teams, assistance will be needed from a number of other groups of people and especially from physiotherapists, chiropodists, and shoe manufacturers and retailers. The role of these individual groups in dealing with the foot problem will be described in succeeding articles in this series.

(Reprinted by kind permission from the February, 1954, issue of "The British Journal of Physical Medicine," published by Butterworth and Co. Ltd.).

\section{GENERAL}

The Private Practitioners' Register is still in the process of compilation. If any member, who has not previously applied, wishes to be included in this Register, please contact Mr. A. Rothberg, W.N.L.A. Rehabilitation Centre, Eloff Street Extension, Johannesburg. It is hoped to publish this Register before the end of the year.

It has been suggested that Post-graduate courses lasting for longer than a week-end may be run from time to time. This would enable more subjects to be covered and may make a long journey more profitable for those who have to come from other centres. Ideas and comments on this suggestion will be welcomed by Miss Blair at the Medical School, University of the Witwatersrand.

We welcome to the Society:-Miss P. R. Chenik, c/o Physiotherapy Department, Krugersdorp Hospital, Transvaal; Miss N. K. Maier, Physiotherapy Department, Middelburg Hospital, Transvaal; Miss K. O. Mansfield, 148, Beach Road, Nahoon, East London; Miss G. D. Morris, "Melrose," Main Road, St. James', Cape; Mrs. O. H. Muller, 6, Danita Court, New Street, Kroonstad, O. F.S.; Miss K. Völker, Physiotherapy Department Klerksdorp Hospital, Transvaal; and Mr. T. W. Woodgate, 3, Ivy Court, Main Road, Plumstead, Cape Town.

The S.A.S.P. has been granted space in the Scientific Exhibition of the 40th South African Medical Congress to be held in Pretoria from 17th-22nd October, 1955. Miss Hazel Baines will be the Convener of our Exhibition, and any suggestions will be welcomed by her. Photographs and "gadgets" will be especially acceptable.

The following were successful in the examination in Electrotherapy held in April of this year by the South African Medical and Dental Council. They are thereby entitled to registration as physiotherapists.

Miss A. Dannecker, Mrs. Fiedler, Miss N. K. Maier, Miss I. M. Ockert, Mrs. M. E. Rehfeld, Mrs. Ribaric, Miss R. Schubert, Miss K. Schlosske, Miss O. Volker, Miss O. von Britzke, Miss Y. von Schrader and Mrs. Waechter.

The O.F.S. Branch is to furnish a stall at the National Council of Women's exhibition of "What Women Are Doing and Can Do" being held in Bloemfontein on August 28 th, 1955.

The University Towns Festival raised over $£ 93,000$, and the organisers wish to thank all students and members of the Society who so willingly gave their help in raising this magnificent sum.

The Constitution Committee of the Society is meeting regularly to draft a new Constitution, and it is hoped that this will shortly be ready. 
TARIFF OF FEES FOR PHYSIOTHERAPISTS (To take effect from 1st August, 1955).

The following Tariff of Fees for Medical Aid Cases has been accepted by the Johannesburg Private Practitioners and comes into effect on 1st August, 1955. Negotiations are still proceeding to increase the rates for travelling. NO FURTHER NOTIFICATION OF THIS TARIFF WILL BE GIVEN.

Massage only

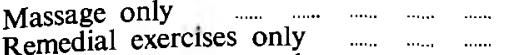

Electrical treatment only $\ldots . . . . . . . . . . . . . . . .$.

Joint or Spinal manipulation or spinal traction

Combined treatments ................................

Diathermy or Ultrasonic treatment (with or without massage)

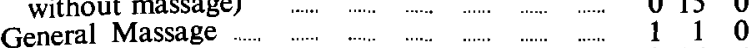

$\begin{array}{lllllllllll}\text { Colonic Lavage } & \ldots . . . & \ldots . . . & \ldots . . . & \ldots . . . & \ldots . . . & \ldots . . & \ldots . . . & 0 & 17 & 6\end{array}$

Electrical reaction tests:

(a) Per single nerve, one group of muscles or tendons

(b) Per one limb

(c) Per whole body

$£ 012 \quad 6$

$\begin{array}{lll}0 & 15 & 0\end{array}$

$\begin{array}{lll}0 & 15 & 0\end{array}$

$\begin{array}{lll}0 & 15 & 0\end{array}$

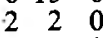

Skin temperature tests:

(a) Skin temperature tests in reference to reflex heating .................................

(b) Skin temperature tests in reference to

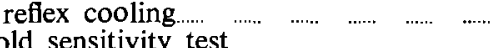

(c) Cold sensitivity test

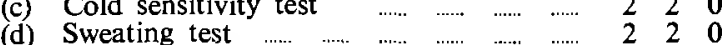

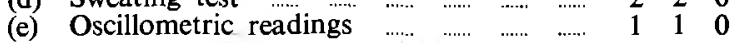

The number of treatment administered to any one patient is limited to 15 . Further treatment may be administered after consultation with the Medical Aid Society of which the patient is a member.

Portable fee (i.e. attendance outside rooms)

026

Mileage fee (to be charged in addition to portable fee). For distance-travelled-both-ways from the rooms or residence, whichever is the nearer to the point of call, $1 / 3$ per mile for every mile in excess of 8 miles provided that the condition of the patient is such that the patient could not attend for treatment at the rooms.

\section{CHANGES OF ADDRESS}

Mr. V. G. Lerm to 2nd Floor, United Building, Plein Street, Stellenbosch, C.P.

Mrs. R. Bremner to P.O. Box 250, Umtali, S. Rhodesia.

Miss D. van der Merwe to c/o Matron, Wynberg Military Hospital, Cape Town.

Mrs. V. Cohen to 43, Blyton Avenue, Savoy Estate, Johannesburg.

Mrs. M. E. Hahn to Ridge Road, Linksfield Ridge, Johannesburg.

Miss F. D. K. Knight to c/o T. C. Knight, Esq., P.O. Box 424, Pretoria.

Miss E. Kope to c/o Mrs. Myer, 7, Oakley Court, Protea Road, Claremont, Cape Town.

Miss G. D. Morris to "Melrose," Main Road, St. James', Cape.

Mrs. J. Lugg, to 1, Harewood Dene, Harewood Drive, Nahoon, East London. London.

Mrs. H. Judge to 1, Sandown Road, Stirling, East

Mrs. D. Baumann to 1, Tudor Court, 14, St. Matthew's Road, East London.

\section{SOUTH AFRICAN
SOCIETY OF PHYSIOTHERAPISTS GROUP ENDOWMENT FUND}

We have pleasure in announcing that a Group Endowment Fund has been inaugurated for members of the South African Society of Physiotherapists and will be underwritten by The Colonial Mutual Life Assurance Society Limited (hereinafter referred to as the Underwriters).

The Fund will enable members of the Society to obtain assurance at a lower cost than is possible with individual contracts and will enable them not only to insure their lives for the benefit of their dependents but to save for their retirement by deduction of regular monthly contributions from salary.

Members of the Society who wish to insure under this scheme must complete a short Proposal Form together with a Stop Order must complete a short Proposal Form together with a Stop
for the deduction of contributions monthly from salary.

The Trustees of the Fund will hold at the Society's headquarters a master policy on the schedules of which will be entered full particulars of each member's assurance.

The benefits consist of guranteed amounts payable at the age selected by the member, or on prior death, and are subject to increase by annual bonus additions. Additional benefits in the form of Cash Payments subject to increase by bonus additions as declared in the Underwriter's Accident Department and waiver of future contributions are payable upon disablement due to certain contingencies prior to the selected age as set out on the master policy.

BENEFITS WILL DEPEND UPON:

(1) The member's age on entry into the scheme;

(2) The monthly contribution to be paid;

(3) The selected age at which the sum assured is payable.

ALL MEMBERS WILL RECEIVE A CERTIFICATE OF ENROLMENT GIVING FULL DETAILS OF CONTRIBUTIONS AND BENEFITS.

In the event of a member leaving the Society, the enrolment will be converted into an ordinary policy with the underwriters. Benefits and contributions will remain unchanged but future contributions will require to be paid direct to the underwriters. Such a policy on the life of a female member may in certain circumstances, be converted into a policy on the life of her husband if he is insurable and not more than 10 years ber senior.

The Fund is similar to that which has operated for the benefit of members of the South African Nursing Association for many years and the Execurive of your Society hope that all members will give the Fund their full support.

CUT HERE.

To the TRUSTEES GROUP ENDOWMENT FUND, S.A. SOCIETY OF PHYSIOTHERAPISTS, P.O. BOX 1106, PRETORIA.

Please supply me with details.

Name.

Address.

Date of Birth

Where employed

How much can you afford to pay each month: 